\title{
Adherence to medications among adults with diabetes mellitus in the urban field practice area of Raja Rajeswari Medical College and Hospital, Bangalore, Karnataka, India
}

Srividya V. ${ }^{1}$, Balaje R. ${ }^{2 *}$

DOI: https://doi.org/10.17511/ijphr.2019.i5.04

\footnotetext{
${ }^{1}$ Srividya V, Department of Community Medicine, Raja Rajeswari Medical College \& Hospital, Bengaluru, Karnataka, India.

${ }^{2 *}$ R. S. Neshant Balaje, Department of Community Medicine, Raja Rajeswari Medical College \& Hospital, Bengaluru, Karnataka, India.
}

\begin{abstract}
Introduction: Poor adherence is likely to lead to increased complications of diabetes resulting in increased costs of health care and increased morbidity and mortality for the population in the long term. The present study was designed to assess the socio-demographic profile and adherence to medications among adults with diabetes mellitus on treatment residing at urban field practice area of a private medical college in Bengaluru, Karnataka. Materials \& Methods: This was a crosssectional study comprising of 150 adults with Diabetes Mellitus residing at Urban Field Practice Area of RajaRajeswari Medical College and Hospital, Bangalore. Data entry was done in MS excel and analyzed in SPSS software. Results: Out of 150 study subjects, it was observed that majority $54(36 \%)$ of the study subjects had disease duration of more than 5 years. High, moderate and low adherence to medication was found among $25(16.67 \%), 91(60.67 \%)$ and $34(22.66 \%)$ of the study subjects respectively. Low adherence was observed to be higher 20(58.8\%) among study subjects with disease duration of more than 5 years as compared to other categories. Co-morbidity was absent in majority $24(70.6 \%)$ of the study subjects with low adherence. Conclusion: It is evident that there is a great need on the part of health care providers to not only prescribe medications to the patients with diabetes mellitus but also make a conscious effort to address the issue of nonadherence to the prescribed medications and other non-pharmacological measures.
\end{abstract}

Keywords: Adherence, Medications, Diabetes Mellitus, Urban

Corresponding Author

R. S. Neshant Balaje, Department of Community Medicine, Raja Rajeswari Medical College \& Hospital, Bengaluru, Karnataka, India.

Email: 92nishanth@gmail.com
How to Cite this Article

Srividya V, Balaje RSN. Adherence to medications among adults with diabetes mellitus in the urban field practice area of Raja Rajeswari Medical College and Hospital, Bangalore, Karnataka, India. Public Health Rev Int J Public Health Res. 2019;6(5):200206.

Available From

https://publichealth.medresearch.in/index.php/ijphr/ article/view/120
To Browse

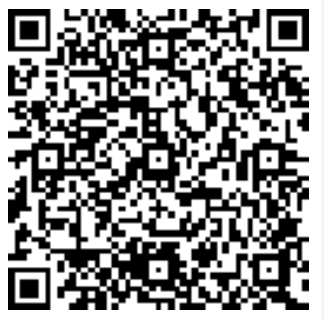

Manuscript Received 2019-10-10

Conflict of Interest No
Review Round 1 2019-10-20

Funding

Review Round 2
$2019-10-26$
Ethical Approval
Yes

Review Round 3

Accepted 2019-10-31

Plagiarism X-checker $8 \%$

(C) 2019 by Srividya V, R. S. Neshant Balaje and Published by Siddharth Health Research and Social Welfare Society. This is an Open Access article licensed under a Creative Commons Attribution 4.0 International License https://creativecommons.org/licenses/by/4.0/ unported [CC BY 4.0]. 


\section{Introduction}

Low adherence to prescribed medication in patients with non-communicable diseases (NCDs) increases risk of hospitalization, development of complication and premature mortality. Adherence is defined as the extent to which a person's behaviour of taking medication, following diet, and/or executing lifestyle changes corresponds with agreed recommendations from the health care provider [1].

The management of diabetes mellitus is multipronged. Majority of patients with type 2 diabetes fail to control glycemia with diet and exercise and require pharmacotherapy-in general, initially monotherapy with oral hypoglycemic agents $(\mathrm{OHA})$; however, owing to the progressive nature of the disease, most of the patients will eventually require combination therapy and ultimately injectable treatments as monotherapy or part of polytherapy. Glycemic control in type 2 diabetes is essential to prevent complications. Hence the holistic approach to the control of diabetes is vital. Adherence is directly related to various factors such as education, knowledge, economic status, forgetfulness, lack of will power \& physician knowledge. Duration of the disease also bears a direct effect on the adherence of the patient to the treatment. The decline in adherence is most rapid after the first 6 months of therapy. Thus, the overall management of type 2 diabetes should address adherence as well as appropriate medications [2].

Assessing adherence to medications and its correlates among patients with non-communicable diseases (NCDs) can help in delivering targeted interventions. Non-adherence to medication plays an important role in increasing the all cause hospitalization, mortality, and out of pocket expenditure among patients with diabetes [3]. Poor adherence to recognized standards of care is the principal cause of development of complications in NCDs. Adherence to medication is essential in order to obtain full therapeutic benefit in diabetes. With this background, this study was undertaken among adults with diabetes mellitus in the urban field practice area of RajaRajeswari Medical College \& Hospital (RRMCH), Bangalore.

\section{Objectives}

01. To assess the socio-demographic profile of diabetic patients in Urban Field Practice Area of RajaRajeswari Medical College \& Hospital, Bangalore
02. To assess the level of adherence to prescribed medication among diabetic patients in the study area

\section{Materials \& Methods}

Study setting: Urban Field Practice Area of RRMCH, Bangalore

Study Design: Cross-sectional Study

Study Duration: 3 Months (February 2019 -April 2019)

Sample Size: 150

Study subjects: Adults with Diabetes Mellitus in the Urban Field Practice Area of RRMCH

Inclusion Criteria: Adults, who are known cases of Diabetes mellitus (on treatment) in the urban field practice area of RRMCH, Bangalore

Exclusion Criteria: Pregnancy and lactation

Study Instrument: Pretested, Semi-Structured Questionnaire and MMAS-8 Questionnaire [4]

Method of data collection: This was a crosssectional study conducted in the urban field practice area of RRMCH among 150 study subjects selected by purposive sampling technique. After getting informed consent, relevant data was collected by interview method using pre-tested, semi-structured questionnaire and MMAS-8 Questionnaire.

Categorization of study subjects according to adherence: Adherence was assessed through eight-item Morisky Medication Adherence Scale (MMAS-8) that has high reliability and validity, and the patients were categorized as follows:

High adherence - a score of 8

Moderate adherence - scores of 6-7

Low adherence-scores $<6$

After categorization the different variables were expressed as percentages

Ethical clearance: This study was granted approval from institutional ethics committee of $\mathrm{RRMCH}$, Bangalore

Statistical analysis: The data was compiled in Microsoft (MS) Excel worksheet and analyzed using SPSS (Statistical Package for Social Sciences) software version 20.0. The descriptive statistics- all quantitative and qualitative data were presented as frequency and percentages. 


\section{Results}

Out of 150 study subjects, it was observed that majority, $70(46.7 \%)$ belonged to the age group of 45-59 yrs. The proportion of males was higher, 82 $(54.7 \%)$ as compared to females $68(45.3 \%)$. Literates were 95(63.3\%).

Occupation-wise, majority, 86 (57.34\%) were employed. $134(89.3 \%)$ were married. Majority, $98(65.3 \%)$ of the study subjects belonged to lower middle class according to Modified Kuppuswamy Classification (2019) of Socio-economic status.

Of the total, study subjects who had not used alcohol, $121(80.7 \%)$ and those who had not used tobacco, $114(76 \%)$ in the past one month constituted the majority. [Table 1]

Table-1: Socio-Demographic characteristics of diabetic adults in the urban field practice area of RRMCH ( $N=150)$

\begin{tabular}{|c|c|c|}
\hline Variable & Number & Percentage \\
\hline \multicolumn{3}{|l|}{ Age (Years) } \\
\hline $30-44$ & 37 & 24.7 \\
\hline $45-59$ & 70 & 46.7 \\
\hline$\geq 60$ & 43 & 28.7 \\
\hline \multicolumn{3}{|l|}{ Gender } \\
\hline Male & 82 & 54.7 \\
\hline Female & 68 & 45.3 \\
\hline \multicolumn{3}{|l|}{ Literacy } \\
\hline Literate & 95 & 63.3 \\
\hline Illiterate & 55 & 36.7 \\
\hline \multicolumn{3}{|l|}{ Occupation } \\
\hline Unemployed & 11 & 7.33 \\
\hline Employed & 86 & 57.34 \\
\hline Housewife & 53 & 35.33 \\
\hline \multicolumn{3}{|l|}{ Marital status } \\
\hline Married & 134 & 89.3 \\
\hline Separated/ Divorced/ Widow & 16 & 10.7 \\
\hline \multicolumn{3}{|l|}{ Socio-Economic Classification } \\
\hline Upper class & 2 & 2.0 \\
\hline Upper middle & 28 & 18.7 \\
\hline Lower middle & 98 & 65.3 \\
\hline Upper lower & 20 & 13.3 \\
\hline Lower & 2 & 0.7 \\
\hline
\end{tabular}

Disease duration more than 5 years was observed among $54(36 \%)$ of the study subjects. Comorbidities was absent in majority, 112(74.7\%) of the study subjects. Study subjects on twice daily regimen were found to be higher, 82 (58\%) as compared to those on once daily and thrice daily treatment regimens.
Study subjects on two or three medications daily constituted the majority $89(57.3 \%)$. [Table 2]

Table-2: Morbidity Characteristics and Treatment profile of diabetic adults in the Urban field practice area of RRMCH

\begin{tabular}{|l|l|}
\hline \multicolumn{1}{|c|}{ Morbidity Characteristics } & \multicolumn{1}{|l|}{ Frequency (\%) } \\
\hline Disease duration (years) & $16(10.7)$ \\
\hline$<1$ & $80(53.3)$ \\
\hline $1-5$ & $54(36.0)$ \\
\hline$>5$ & \multicolumn{2}{|l|}{} \\
\hline Other co-morbidities & $38(25.3)$ \\
\hline Present & $112(74.7)$ \\
\hline Absent & \multicolumn{2}{|l|}{} \\
\hline Regimen & $59(37.3)$ \\
\hline Once daily & $82(58.0)$ \\
\hline Twice daily & $9(4.7)$ \\
\hline Thrice daily & $53(37.3)$ \\
\hline Number of Medication & $89(57.3)$ \\
\hline One & $8(5.4)$ \\
\hline Two-three &
\end{tabular}

Table-3: Distribution of Socio-Demographic Characteristics with Adherence Levels among Diabetic Adults in Urban Field Practice Areas of RRMCH

\begin{tabular}{|c|c|c|c|c|}
\hline Characteristics & $\begin{array}{l}\text { Low } \\
\text { Adherence }\end{array}$ & $\begin{array}{l}\text { Moderate } \\
\text { Adherence }\end{array}$ & $\begin{array}{l}\text { High } \\
\text { Adherence }\end{array}$ & $\begin{array}{c}\text { Total } \\
(\mathrm{N}=150)\end{array}$ \\
\hline \multicolumn{5}{|l|}{ Age (years) } \\
\hline $30-44$ & $7(20.4)$ & $21(23.1)$ & $9(36)$ & $37(24.66)$ \\
\hline $45-59$ & $10(29.6)$ & $50(54.9)$ & $10(40)$ & $70(46.67)$ \\
\hline$>60$ & $17(50)$ & $20(22.0)$ & $6(24)$ & $43(28.67)$ \\
\hline \multicolumn{5}{|l|}{ Gender } \\
\hline Male & $18(52.9)$ & $50(54.9)$ & $14(56)$ & $82(54.66)$ \\
\hline Female & $16(47.1)$ & $41(45.1)$ & $11(44)$ & $68(45.34)$ \\
\hline \multicolumn{5}{|l|}{ Literacy } \\
\hline Literate & $17(50)$ & $64(70.3)$ & $14(56)$ & $95(63.34)$ \\
\hline Illiterate & $17(50)$ & $27(29.7)$ & $11(44)$ & $55(36.66)$ \\
\hline \multicolumn{5}{|l|}{ Occupation } \\
\hline Unemployed & $3(8.8)$ & $5(6.6)$ & $3(12)$ & $11(7.33)$ \\
\hline Employed & $17(50)$ & $52(57.1)$ & $17(68)$ & $86(64.66)$ \\
\hline Housewife & $14(41.2)$ & $34(36.3)$ & $5(20)$ & $53(35.33)$ \\
\hline \multicolumn{5}{|l|}{ Marital Status } \\
\hline Married & $25(73.5)$ & $85(93.4)$ & $24(96)$ & $134(89.34)$ \\
\hline $\mid \begin{array}{l}\text { Separated/Divorc } \\
\text { ed/ Widow }\end{array}$ & $9(26.5)$ & $6(6.6)$ & $1(4)$ & $16(10.66)$ \\
\hline \multicolumn{5}{|c|}{ Socio-economic classification } \\
\hline Upper class & 0 & 0 & $2(8)$ & $2(1.34)$ \\
\hline Upper middle & $10(29.4)$ & $11(11.1)$ & $7(28)$ & $28(18.66)$ \\
\hline Lower middle & $15(44.2)$ & $71(78)$ & $12(48)$ & $98(65.34)$ \\
\hline Upper lower & $8(23.5)$ & $8(8.8)$ & $4(16)$ & $20(13.33)$ \\
\hline
\end{tabular}




\begin{tabular}{|c|c|c|c|c|}
\hline Lower & $1(2.9)$ & $1(2.1)$ & 0 & $2(1.33)$ \\
\hline \multicolumn{5}{|c|}{ Alcohol use (past 1 month) } \\
\hline Yes & $10(29.4)$ & $16(17.58)$ & $3(12)$ & $29(19.34)$ \\
\hline No & $24(70.6)$ & $75(82.42)$ & $22(88)$ & $121(80.66)$ \\
\hline \multicolumn{5}{|c|}{ Tobacco Use (Past 1 Month) } \\
\hline Yes & $9(26.5)$ & $23(25.2)$ & $4(16)$ & $36(24)$ \\
\hline No & $25(73.5)$ & $68(74.8)$ & $21(84)$ & $114(76)$ \\
\hline
\end{tabular}

High, moderate and low adherence to medication was found among 25 (16.67\%), 91(60.67\%) and 34 $(22.66 \%)$ of the study subjects respectively.
The proportion of low adherence was found to be higher among study subjects aged more than 60 years. Lower middle class of socioeconomic status, male gender, married and employed categories constituted the majority of study subjects with low adherence. In this study, proportion of study subjects who had not used alcohol and those who had not used tobacco in the past one month constituted the majority across high, moderate and low adherence categories. [Table 3].

Table-4: Distribution of Treatment Profile with Adherence Levels among Diabetic adults in Urban Field Practice Areas of RRMCH

\begin{tabular}{|c|c|c|c|c|}
\hline Characteristics & Low Adherence & Moderate Adherence & High Adherence & Total $(\mathrm{N}=\mathbf{1 5 0})$ \\
\hline \multicolumn{5}{|l|}{ Disease duration(years) } \\
\hline$<1$ & $3(8.8)$ & $9(9.9)$ & $4(16)$ & $16(10.67)$ \\
\hline $1-5$ & $11(32.4)$ & $56(61.5)$ & $13(52)$ & $80(53.33)$ \\
\hline$>5$ & $20(58.8)$ & $26(28.6)$ & $8(32)$ & $54(36)$ \\
\hline \multicolumn{5}{|l|}{ Other co-morbidities } \\
\hline Present & $10(29.4)$ & $24(26.4)$ & $4(16)$ & $38(25.4)$ \\
\hline Absent & $24(70.6)$ & $67(73.6)$ & $21(84)$ & $112(74.6)$ \\
\hline \multicolumn{5}{|l|}{ Regimen } \\
\hline Once daily & $8(23.5)$ & $36(39.6)$ & $15(60)$ & $59(39.33)$ \\
\hline Twice daily & $22(64.7)$ & $52(57.1)$ & $8(32)$ & $82(54.67)$ \\
\hline Thrice daily & $4(11.8)$ & $3(3.3)$ & $2(8)$ & $9(6)$ \\
\hline \multicolumn{5}{|l|}{ Number of Medication } \\
\hline One & $8(23.5)$ & $33(36.3)$ & $12(48)$ & $53(35.33)$ \\
\hline Two-three & $22(64.7)$ & $55(60.4)$ & $12(48)$ & $89(59.34)$ \\
\hline More than Four & $4(11.8)$ & $3(3.3)$ & $1(4)$ & $8(5.33)$ \\
\hline
\end{tabular}

Low adherence was observed to be higher among study subjects with disease duration of more than 5 years $20(58.8 \%)$ as compared to the study subjects in disease duration $<1 \&>5$ years categories. Comorbidity was absent in majority, $24(70.6 \%)$ of the study subjects with low adherence. The proportion of low adherence was found to be higher among study subjects on twice daily drug regimen as compared to once \& thrice daily treatment regimens. Study subjects taking two or three medications daily constituted the majority $22(64.7 \%)$ in the low adherence category. [Table 4]

\section{Discussion}

Diabetes mellitus has become an important public health concern which needs immediate attention of the healthcare professionals. Its optimum control is a major challenge to patients and poses a great burden on the health care system and national economy [2].
This study conducted among adults with diabetes mellitus on treatment consisted of details of sociodemographic characteristics, morbidity profile, treatment received and adherence to medication. In this study, $70(46.7 \%)$ of the diabetics belonged to the age group of 45-59 yrs. Similar findings were observed in the study by Shukla P et al [2] wherein the mean age of the participants was $57.52 \pm 12.33$ years.

Substance abuse often compromises the glycemic control of patients further reducing their quality of life [2]. In this study, majority of the study subjects $121(80.7 \%)$ and $114(76 \%)$ had not used alcohol and tobacco in the past one month respectively. Similar findings were observed in the study by Thekkur $P$ et al [5] wherein, $12.8 \%$ and $10.3 \%$ of the participants reported current use of alcohol and tobacco respectively.

Majority, $80(53.3 \%)$ had a disease duration of 1-5 yrs. However, in a study conducted at Patiala [2], 
$29 \%$ of the patients were diagnosed with diabetes between the period of 1-5 year. Thekkur $P$ et al [5] observed that co-morbidities was absent in $93.2 \%$ of the participants similar to our study (74.7\%). However in the study by Shukla P et al [2] at least one associated co-morbidity such as hypertension, asthma or osteoarthritis, etc. was present in $57 \%$ of the study population.

In this study, patients taking twice daily treatment regimen were found to be higher 82 (58\%) however, in a study conducted at Puducherry [5], majority, $114(40.6 \%)$ were consuming drugs only once in a day.

In the present study, patients on two to three medications daily constituted the majority 89 (57.3\%) similar to the findings of Thekkur $\mathrm{P}$ et al [5] who observed that, of the total, $114(40.6 \%)$ were consuming drugs only once in a day and around $164(58.4 \%)$ had to consume two to three drugs per day.

In this study, high, moderate \& low adherence to medication was found among 25(16.67\%), $91(60.67 \%) \& 34(22.66 \%)$ of the study subjects respectively. In the study by Shukla $P$ et al [2], analysis of MMAS- 8 item scores of patients showed that $52 \%$ of patients had low adherence, $29 \%$ had medium while $19 \%$ had high adherence to the treatment.

Arulmozhi et al [6] in a study at Puducherry using MMAS-8 scale reported low adherence to medication in $39 \%$ patients. However, in a community based cross-sectional study conducted in rural village of Kerala [7] it was observed that $74 \%$ of diabetic patients were less adherent to medication (according to MMAS-8).

The proportion of low adherence in our study was found to be higher i.e., $17(50 \%)$ among patients aged more than 60 years. Similarly Shaimol $T$ et al [8] observed that when the age of the patient increased, medication adherence decreased. However in the study by Thekkur $P$ et al [5] low adherence was observed in $19(12.8 \%)$ of the participants above 60 yrs.

Gender-wise, in a study conducted by Shaimol T et al [8] adherence was observed to be more among males $(24 \%)$ as compared to females $(20.8 \%)$, this finding is similar to our study. In the same study [8] the unmarried group (78.3\%) showed higher adherence compared to married group (18.3\%) this is in contrast to the present study.
The proportion of low adherence was higher among the employed. Thekkur $\mathrm{P}$ et al [5] observed that lesser age, higher education, being housewife and tobacco use were significantly associated with low adherence to medication on univariate logistic regression.

In this study, low adherence was observed to be higher i.e., 20(58.8\%) among study subjects with disease duration of more than 5 years as compared to the other disease duration categories. However, Arulmozhi et al [6] reported that shorter duration of disease ( $<1$ year) was found to be associated with low adherence to medication. Co-morbidity was absent in majority, $24(70.6 \%)$ of the study subjects with low adherence in our study. Similar findings were observed by Thekkur $P$ et al [5] wherein having only diabetes was significantly associated with low adherence to medication.

Majority, $24(70.6 \%)$ of the patients in the category of low adherence in this study had not used alcohol in the past one month. Similarly, majority, $25(73.5 \%)$ had not used tobacco in the past one month. Whereas in the study at Puducherry [5], factors related to lifestyle like smoking and alcohol were associated with low adherence.

In the present study, beyond the twice daily and two or three drug treatment regimens, there was no increase in the proportion of study subjects with increase in the number or frequency of medication in the low adherence category. However, in the study by Thekkur $P$ et al [5], factors related to medication like increase in number and frequency of drugs was associated with low adherence.

This was a cross-sectional study, measures of adherence, diagnosis of diabetes and other factors were self-reported. As described in the study by Sankar $U$ V et al [7], self-reported compliance usually overestimates true adherence rates. So, it is possible that the rate of low adherence in the community maybe higher than the estimates found in this study. However, this study highlights that low adherence to medications poses a significant challenge to the control of diabetes mellitus in the community.

\section{Conclusion}

Studies conducted in the past have reported that adherence rates can be improved by disease and treatment specific instructions to the patients along with adequate motivation and constant reinforcement by the health care providers. 
The present study has shown that low adherence to medications was observed among $22.66 \%$ of the patients while high adherence was found in only $16.67 \%$ of the diabetic adults. Hence there is a need for targeted education programs for health care providers and for patients in order ensure that the patients obtain full benefit of the treatment which would help in improving the quality of life.

Relevance of the study: In view of the significant public health challenge posed by Diabetes Mellitus, this study highlights the importance of good adherence to the prescribed medications among the patients which would help in reducing the burden of the disease on the individual and the community.

\section{Authors' Contribution}

Srividya V- Concept, design, data review, preparation \& finalization of the manuscript and revising it for intellectual relevance. R. S. Neshant Balaje - Literature search, collection, analysis, interpretation \& presentation of data.

\section{Limitation}

Sample size was relatively small hence generalizability of this study to other population groups is limited.

\section{Acknowledgement}

We would like to express our gratitude to the members of the community residing at the urban field area of our institution.

\section{Reference}

01. Adherence to long-term therapies- evidence for action. World Health Organization. 2003 [cited 2019 Feb 7] 135-145. Available from:

[Article] [Crossref]

02. Shukla P, Palta S, Gupta A, Sehgal VK. A study to evaluate compliance in patients of diabetes $m$ ellitus in a North-Indian tertiary care hospital. I nt J Basic Clin Pharmacol. 2018 Mar; 7(3)480-5. DOI: [Article] [Crossref]

03. Ho PM, Rumsfeld JS, Masoudi FA, McClure DL, Plomondon ME, Steiner JF, Magid DJ. Effect of Medication Nonadherence on Hospitalization and Mortality Among Patients with Diabetes Mellitus. Arch Intern Med. 2006;166(17)1836-1841.

doi: 10.1001/archinte.166.17.1836. [Article] [Crossref]
04. Morisky DE, Ang A, Krousel-Wood M, Ward HJ. Predictive validity of a medication adherence measure in an outpatient setting. J ClinHypertens (Greenwich). 2008 May; [cited 2019 Jan 3]10(5)348-354.

Available from: [Article] [Crossref]

05. Thekkur P, Reddy MM, Ramaswamy G, Naik B, Lakshminarayanan S, Kumar Saya G. Medication adherence and its correlates among diabetic and hypertensive patients seeking care from primary health center, India. Int J Curr Pharm Rev Res. 2015 [cited 2019 Feb 17];7(2)33-9.

Available from: [Article] [Crossref]

06. Arulmozhi S, Mahalakshmy T. Self-care and medication adherence among type 2 diabetics in Puducherry, Southern India- A hospital based study. J Clin Diagn Res. 2014 [cited 2019 Feb 4];8(4)UC01-UC03.

Available from: [Article] [Crossref]

07. Sankar UV, Lipska K, Mini GK, Sarma PS, Thankappan KR. The adherence to medications in diabetic patients in rural Kerala, India. Asia Pac J Public Health. 2015 [cited 2019 Feb 11];27(2)NP513-523.

doi: $10.1177 / 1010539513475651$. Available from: [Article] [Crossref]

08. Shaimol T, Biju CR, Anilasree BP, Jayakrishnan SS, Babu G. Medication Adherence to Oral Hypoglycemic Agents in Type 2 Diabetic Patients. Journal of Pharmaceutical Research \& Clinical Practice. 2014 [cited 2019 Mar 23];4(2)8-12.

Available from: [Article] [Crossref] 